\title{
The value of management in the digitalisation era: evidence from an Italian museum
}

\section{Viviana D'Angelo}

\author{
Uninettuno University, \\ Corso Vittorio Emanuele II, \\ 39, 00186 Rome, Italy \\ Email: viviana.dangelo@uninettunouniversity.net
}

\begin{abstract}
The digital transformation of the world of museum is changing not only the way the visitors enjoy the museum experience, but also the way that museums deliver the experience, requiring a process of change and adaptation into the museum organisation. In this scenario, the museum management plays a crucial role addressing and fostering those challenges, promoting the exploitation of the resources available, and encouraging a continuous cooperation with institutions. Through a single case study of an archaeological museum located in central Italy, we analyse how the change in the managerial staff has been essential to promote a change towards the digitalisation process, and how the background and the previous experience of the top manager further simplify the process.
\end{abstract}

Keywords: museum digitalisation; change management; Industry 4.0; cultural tourism; organisational change.

Reference to this paper should be made as follows: D'Angelo, V. (2020) 'The value of management in the digitalisation era: evidence from an Italian museum', Int. J. Digital Culture and Electronic Tourism, Vol. 3, No. 1, pp.94-108.

Biographical notes: Viviana D'Angelo is a $\mathrm{PhD}$ student in Management at LUISS Guido Carli. Her major research interests include frugal innovation, resource-constrained innovation, agent-based modelling for innovation studies. She has been visiting $\mathrm{PhD}$ student at Royal Institute of Technology (Stockholm) and Sant'Anna School of Advanced Studies (Pisa).

\section{Introduction}

Digital technologies are becoming more and more integrated with industry and society, in a way that is transforming many aspects of the life. Digital technology uses information and communication technology (ICT) in a comprehensive approach that promotes employment, a better quality of life, social participation, and social integration; it includes many types of integration within the digital society, including digital social inclusion, digital citizenship, and digital social fusion (Mcloughlin and Lee, 2010; Noh and Tolbert, 2019). Digital inclusion does not simply entail improving access to information and communications through infrastructure and technology innovation, but it also addresses the full spectrum of human life (Noh and Tolbert, 2019). 
The digital revolution has involved also museums, starting from the introduction of websites to the use of digital technology to enhance the experience for visitors, leading to a different space for interaction among the various cultural stakeholders (Hooper-Greenhill, 1999). As an organisational change, it is expected to have a significant impact on museum organisation and management, resulting in the need of an appropriate managerial support in order to foster the process (Tsoukas and Chia, 2002; Van De Ven and Poole, 2005). In this respect, the importance of the museum management to prompt the digital revolution into the museum activity is essential, as well as the importance of the managerial team. Furthermore, the process of digital transformation represents an important step for museums, involving in one hand changes in every activity that are normally conducted as established routines (Volkoff et al., 2007), and on the other hand, it represents an important turning point for the museum as organisation.

Transformational change can occur in response to or in anticipation of major changes in the organisation's environment or technology. In addition, these changes often are associated with significant revision of the organisation structure, which, in turn, may require modifying internal structures and processes as well as its corporate culture to support the new direction and the relation with the external environments, in particular customers and institutions. Such fundamental change entails a new paradigm for organising and managing the museum conceived as an organisation. It involves different ways of perceiving, thinking, and behaving in organisations. A translation toward this new way of operating requires senior executives to take an active leadership role. The change process is characterised by considerable innovation and members discover new ways of improving the organisation and adapting it to changing conditions (Cummings and Worley, 2009). The importance of the single individuals, especially at the top management positions, plays a crucial role for the future direction of an organisation: in fact, taking into account the micro-levels of the routines at the single individual level is crucial to understand how strategic and behavioural pattern of the firms are initiated, in line with the micro-foundations at the level of the individual managers (Barney and Felin, 2013; Felin and Foss, 2012; Gavetti, 2005; Helfat and Peteraf, 2015; Teece, 2007). From a human resource perspective, the individual-role dimension plays a crucial role in managing tension associated with organisational change and transformation, becoming essential to attain strategic agility (Burgess et al., 2015).

Furthermore, since the process of change is triggered by environmental and internal disruptions, it need to be monitored, in order to make the process as smooth as possible, avoiding internal conflict and internal resistance to the process of change (Hannan and Freeman, 2006; Kelly and Amburgey, 2018; Tripsas and Gavetti, 2002). In fact, the organisation inertia (Gilbert, 2005), defined as the tendency of an organisation to continue on its current trajectory, can lead the organisation, in this specific context museums, to refuse to embrace the overall changing of society and industry, remaining embedded in the past. In this sense, Chia (2002) argue that there has always been change, and organisations act and absorb the immanent forces of change by institutionalising social habits and patterns of behaviour so that then it becomes possible for us communicate with each other and to 'shape' the world.

In this scenario, our paper explores the main drivers guiding the museums towards a successful digitalisation process. Indeed, the main purpose is to dig deeper into the main challenges encountered, the barriers faced, which are the relevant actors. The study has 
been conducted through an explorative case study about the digital activities of the Archaeological Museum of Atina, in the central Italy. This project involved the 'virtualisation' of existing cultural heritage related to the medieval times of the region and the digital preservation of historical assets (text and images) held by other organisations in the region. The case study methodology enables to narrow down the phenomenon object of interest and to capture aspects that will not be extrapolated with other research method.

This research contributes to the literature of museum digitalisation by enriching the current knowledge of how the digitalisation process occurs in museum context. Furthermore, it provides important insights to practitioners about how the challenges of digitalisation of museum should be conducted to avoid internal resistance and to foster the change.

\section{Literature}

The emergence of the Industry 4.0 paradigm had a significant impact also in the museum industry: in this sense, the Industry 4.0 is defined as the last industrial revolution triggered by the internet, which allows communication between humans as well as machines throughout the use of digital technologies (Brettel et al., 2014). In this sense, museums are evolving together with the industry and society towards a more digitalised sector.

The digital experience involves both the use of digital devices such as Smartphone and apps (Solima et al., 2016; Yoshimura et al., 2014), and the use of digital tools such as augmented reality and audio-visual tools to provide virtual experiences (Pallud and Straub, 2007; Pallud, 2017; Soren, 2009). Other scholars emphasised the role of digital tools to change the visitor's experience (Carrozzino and Bergamasco, 2010; Schaper et al., 2018), or focused on the importance of innovation activities for museums (Camarero et al., 2011; Garrido and Camarero, 2010).

From an organisational standpoint, the digitalisation that is sweeping across the society implies a significant change into the organisations and routines: the sensitiveness of the task is translated into the need to handle it with extreme caution, as it constitutes an example of change in organisational process (Daly and Ballantyne, 2009).

The impact of the changes into the organisations has been extensively addressed by literature. In particular, a stream of research emphasises the importance of the single individuals, by considering the process of change as the result of new experiences obtained through interactions, and that the change is strictly embedded into the human actions, where the organisation is constituted and shaped by change (Tsoukas and Chia, 2002). In this view, change occurs when the processes operate in a manner that is reified by observer(s) as changing the organisation (Van De Ven and Poole, 2005). A different stream of research focuses on the different models for change and how to address it (DuBrin, 2013; Van de Ven and Sun, 2018).

One of the key issues regarding the process of change in the organisations is the resistance to change (Cummings, 2008). Possible causes of the resistance are structural inertia, work habits, fear of the unknown, powerful interests, and members' security needs (Agocs, 1997; Ford et al., 2014).

Within this framework, the role of the management practice plays a pivotal role to address and promote the change (Ansari et al., 2014). In particular, previous studies have 
identified the key driver of the organisational change: the importance of the leadership (Griffin, 1987), and the importance of spreading organisational culture (Schein, 2006). In the specific context of the museums, this issue is further amplified by the fact that museum managers are usually scholars working as part time managers, devoting the rest or their time to research, doing the best to balance both activities (Griffin, 1987). Furthermore, the peculiar context of museum requires that managers to have competences about arts and cultural heritage, and a managerial formation, thus increasing the complexity of the task (Proctor, 2010). Overall, the importance of museum management in spreading the organisational cultures plays the same role in as any organisation in addressing organisational change (Weinberg and Lewis, 2009).

\section{Methodology}

The study has been conducted through a case study approach. Case studies enable to explain, describe or explore events or phenomena in the everyday contexts in which they occur (Eisenhardt, 1989; Yin, 1981). Case study research is a very useful method because it allows expansion and generalisation of theories by combining the existing theoretical knowledge with new empirical insights (Yin, 2014). A single case study was considered to represent the best means of acquiring deep and contextual insight to generate and build a theory (Yin, 2009). In addition, the case study approach lends itself well to capturing information on more explanatory 'how', 'what' and 'why' questions, such as 'how' is the intervention being implemented and received on the ground, enabling to exploring and capturing features of the observed phenomenon which may not be observed with a different methodology.

The object of this case study is the Archaeological Museum of Atina and Valle di Comino, located in the province of Frosinone, central Italy. The museum, beyond the traditional exhibition of archaeological finds discovered between VII and III sec. BC, hosts also two multimedia rooms about the medieval history of the region. These two rooms provide two different digital experiences that complete the museum journey.

The analysis was conducted through both primary and secondary data. Primary data have been collected through semi-structured interviews with the museum managements, while secondary data (archival data, websites, institutional communications of the museum), have been analysed to complete the information gathered with the primary sources. Data analysis was conducted by using open and axial coding techniques (Strauss and Corbin, 1998), to process and categorise the qualitative data collected and our theoretical contributions.

\section{The case: the archaeological museum of Atina and Valle di Comino}

The Archaeological Museum of Atina and Valle di Comino is part of the Technological District of the Cultural Heritage of the Lazio region, and it was planned within a framework program including various institutional participant like Regione Lazio, which is the local authority, the Ministry of Education, ministry of Economic Development and Ministry for Cultural Heritage. The district is managed by Filas, a public company in the region Lazio, whose mission is to enhance and support development and innovation on a regional scale. The district's aim is to support and improving all kind of initiatives for the 
preservation of the cultural heritage of the region, thus sustaining the economy of the tourism. The Archaeological Museum of Atina and Valle di Comino are included in the Lazio Futouring project, an integrated system of pilot projects that aim to increase the attractive potential of the cultural heritage of the region Lazio. The project has been financed by Regione Lazio and Filas as its public company, while the multimedia contents has been realised by a pool of three different external developers together with the local university, in collaboration also with writers and voice-over actor to create the contents. The managerial aspects of the museum are issued by an external cooperative (representing the managerial team), paid by the Municipality of Atina, which is in turn the principal lender of the museum.

\subsection{The digital experiences}

The Archaeological Museum of Atina offers two different digital experiences in two different 'digital rooms', both of them sharing the same basic them of talking about the Middle Age in the geographical area of the museum (the province of Frosinone - central Italy):

- $\quad$ Room 1 - Medioevie: It offers three multimedia station where the user can experience various activities like exploring three different storytelling of three different characters (a knight, a monk and a pilgrim), reading an old illuminated manuscript, consulting old manuscripts from a digital historical library.

- Room 2: Multimedia station powered by Xbox Kinect and equipped with a sensor that allows the visitor to use its own body movements to enter medieval environments or to move and enlarge the 'talking' frescoes (fake dialogues explain the situation and the happening of the work).

The first digital experience of the room 1 in turn hosts three different multimedia stations, all of them supported by the touch screen technology:

- Station 1: In the first station the visitors retrace the path from Anagni to Atina (where the museum is located) of three different characters, a monk, a pilgrim, and a knight; each path shows different intermediate step based on the character that the visitor has chosen, as shown in Figure 1. For example, by choosing the path of the knight, the visitor can explore the ancient castles and fortifications located along the path, reading the history and virtually entering into the place (thanks to the Google Map 3D technology) as shown in Figure 2.

- Station 2: In the second station, the visitors can virtually read some old medieval illuminated manuscripts, preserved in other local museums and not accessible for the consultation (Figure 3). The original manuscripts have been scanned in high resolution, enabling the user to enlarge the image to focus on particular detail, normally not visible through the traditional 'live' consultation; an additional tool enriches the experience providing the explanation of the process of making a scroll in the Middle Ages.

- Station 3: The third station is an electronic lectern where the user experiences a virtual access to the ancient library of the Benedictine Abbey of Montecassino. The Library of the Montecassino Abbey, like many religious institutions, carried out the task of producing and preserving written culture, and nowadays its rich book heritage 
includes 1,500 codes, 2,000 parchments, 198 incunabula, over 2,000 16th century and a broad musical background. The Benedictine monks of Montecassino, besides the sacred texts, copied many treasures of classicism and invented a new script, the famous 'beneventana' which, formed at the end of the 8th century due to the influence of scribes from the north, spread rapidly in the major writing centres in southern Italy and had a life spanning five centuries. The station allows the consultation of six of the thirty-two tomes of the 'De Universo', considered by historians the ancient medieval encyclopaedia (Figures 4-5).

Figure 1 Multimedia station to retrace the path from Anagni to Atina (see online version for colours)

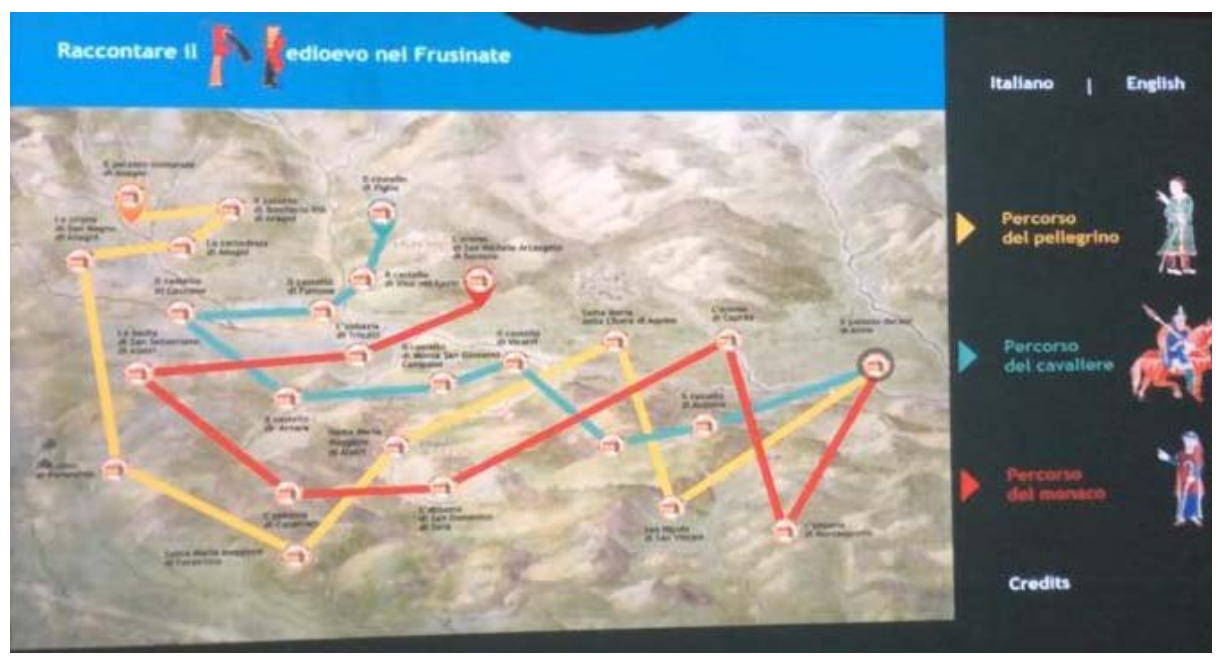

Figure 2 Exploration of the selected path with Google Map 3d technology (see online version for colours)

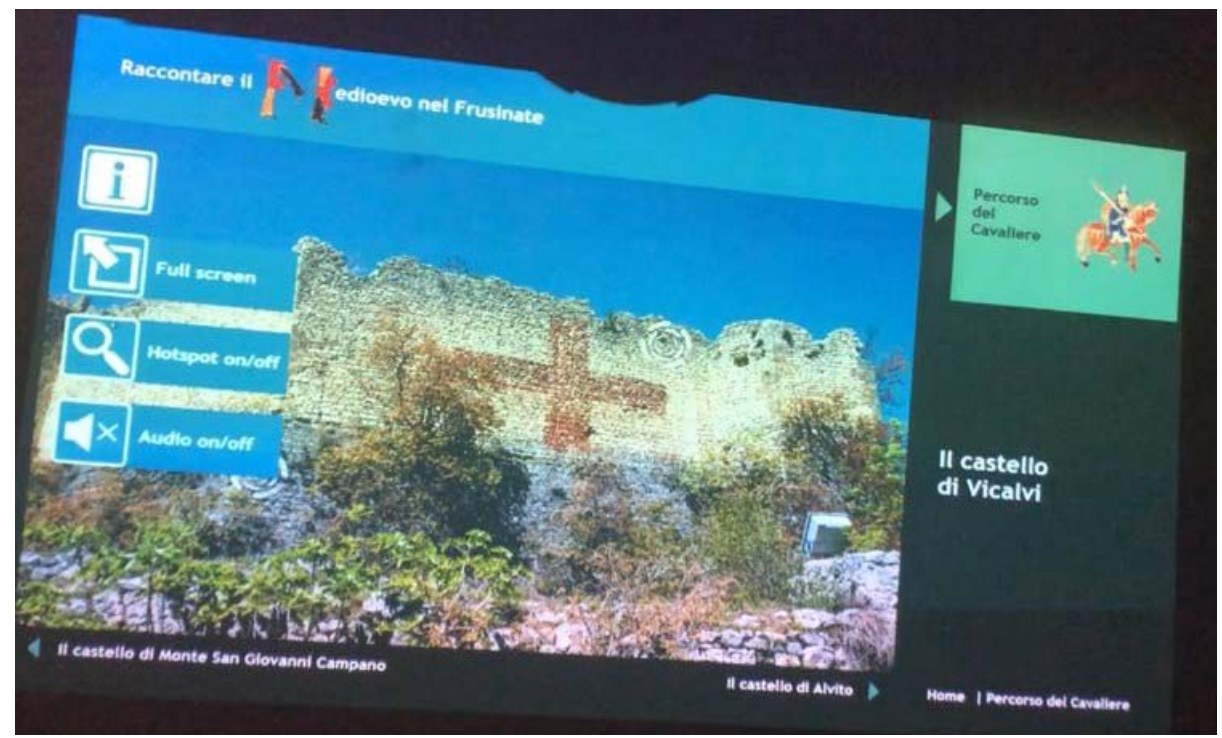


Figure 3 Virtual augmented medieval manuscript (see online version for colours)

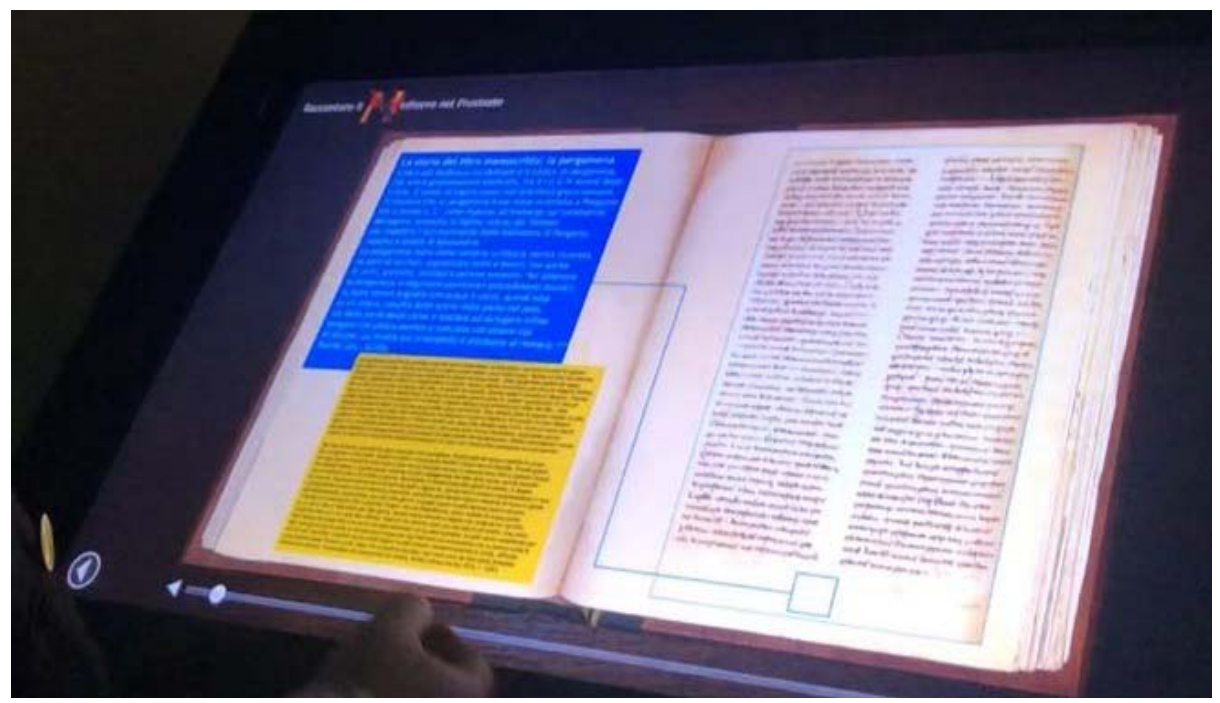

Figure 4 Digital reproduction of the library of the Benedictine Abbey of Montecassino (see online version for colours)

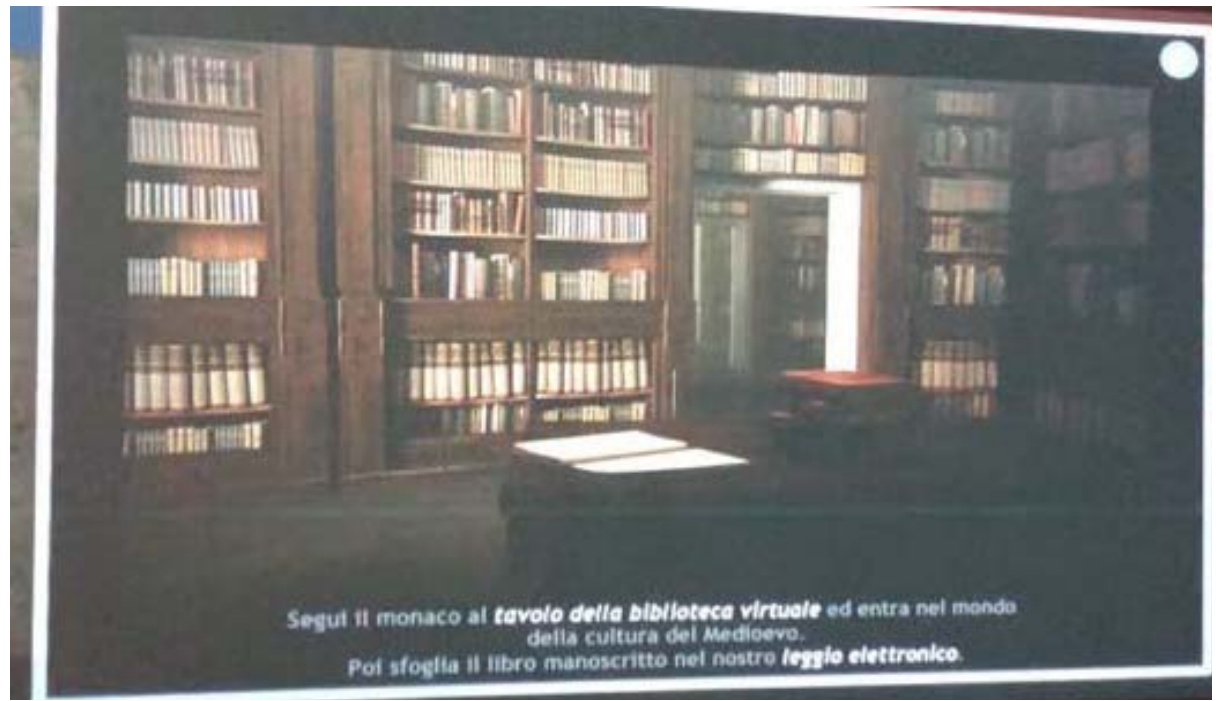

The second room offers a different and even more interactive digital experience. The room is equipped with an Xbox Kinect tool (the Kinect is a motion sensing input devices produced by Microsoft, and it was developed as a gaming accessory for Xbox 360, the Microsoft console videogame). The Kinect is based around a webcam-style peripheral, it enables users to control and interact with the computer through a natural user interface using gestures. In particular, the users can virtually enter in various different historical sites, all of them located in the province of the Archaeological Museum of Atina. One of 
the most interesting aspect of this experience is that the user can choose between various historical sites where the access is normally not allowed. The users can explore the indoor environment of the sites and zooming into the details that the visitor is interested in, or listening the explications of the frescos, painting or monuments, or by choosing to listen a fictional dialogue among the character of a painting, to experiment a more immersive experience, as shown in Figure 6.

Figure 5 Extract from the digitalized ancient encyclopaedia (see online version for colours)

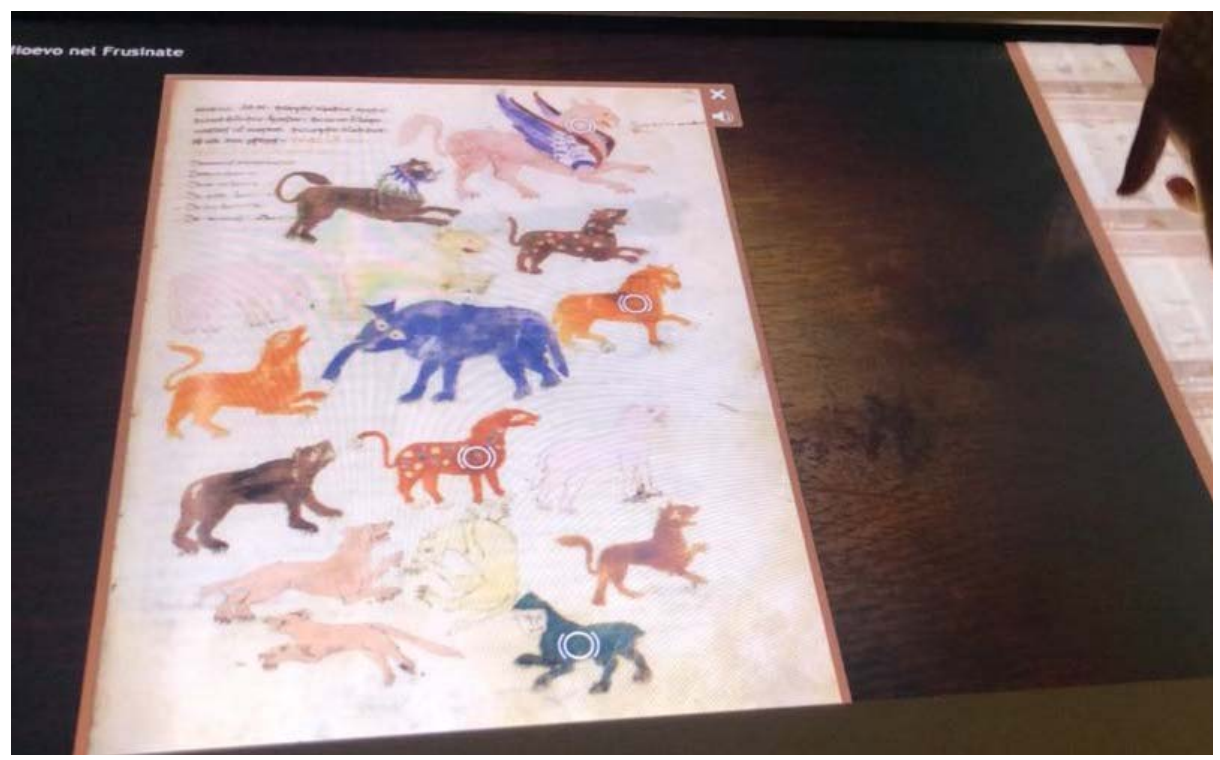

Figure 6 Exploration of a crypt through augmented reality (see online version for colours)

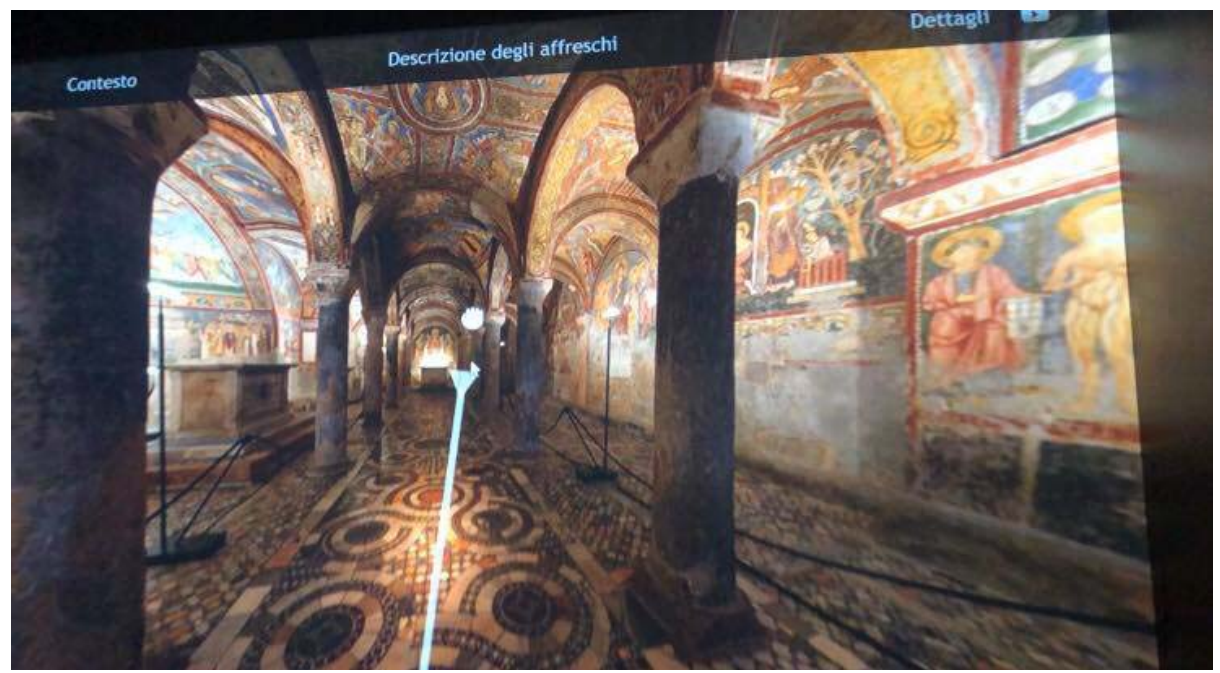




\title{
4.2 The leading role of the different actors in the digitalisation process
}

The process of digitalisation has involved a multiplicity of actors. The peculiar entity of museum, which is a public legal entity, requires analysing the hierarchy of the most influential actors that were involved in the process.

- Institutional participant: They allocate funds, promoting and financing digitalisation projects, acting as resource allocators (Bassanini et al., 2001; Rodrik et al., 2004) and stimulating innovation across public institutions such as museum.

- Technology providers: External providers of all the digital tools and the digital platforms to provide the virtual experience. They are in charge of the design and contents of the multimedia tools, including designing the experience and make it usable for a wide range of users, and including the digitalisation of the content such as the artworks and the descriptions.

- Managerial staff: External cooperative in charge of managing and directing all the matters relating to the museum, visiting hours, maintenance. It plays a crucial role in addressing the vision and mission of the museum and it has the decision-making power on the museum's activities.

\subsection{The proactive role of management}

The role of the management has been crucial in the development and exploitation of the digital tools of the museum. In this sense, the interview with the museum director shows as the change in the managerial staff has represented a turning point for the museum history:

\begin{abstract}
"We were still not here when the project Medioevie took place, there was a different managerial staff at the time, but the multimedia room were kept unaccountably closed; as soon as we found out that there were these interesting initiatives, we immediately started to fight to activate the multimedia room, working on the promotion for cultural institutions and on the institutional communications to promote the project as much as possible."
\end{abstract}

The multimedia room need of a specific consideration because of their peculiarity respect to the traditional museum experience. Notably, the user's fruition of such experience is individual, each visitor can experiment the digital experience one at a time, and in this sense the role of the museum management is crucial to handle the visitors and to enable all of the visitors to enjoy the experience. Also, the multimedia tools require the acquisition of different capabilities respect to the traditional capabilities required for a curator. All of these aspects make the role of the museum management a fundamental element in the digitalisation process, shaping the vision and mission, addressing the organisational aspects, promoting an innovative culture, and fostering the change.

The background and the education of the top manager plays a pivotal role in shaping the organisation (Hambrick and Mason, 1984), as the top manager reports:

"When arrived here, we saw all of this, and I said that is awesome, incredible, we could do a lot of activities with that. Therefore, I designed a first lab. The digital rooms were ready but closed, because there were no personnel in charge of the digital rooms. They had a guardian for the museum, but he had not the background, or the competencies, or the education to deal with all of that. My team and I have previous experience on museum projects, we work with local 
institutions, and we immediately saw the potential of the digital tools, and we designed a unique experience combining both traditional museum experience and the new digital experience, everything settled in the Middle Ages."

It is not surprising that a coherent and specific background education is very important to pursue the mission of the organisation, because the education indicates a person's knowledge and skill base and define the cognitive base of an individual. Evidence from the literature shows that consistent the level of education (either of the CEO or other central actors) is positively related to receptivity to innovation (Becker, 1970; Kimberly and Evanisko, 1981).

\subsubsection{Role of management in relationship with institutions}

The role of the museum manager plays a further crucial role also in addressing the relationship with institutional actors. According to the International Council of Museums (ICOM), a museum is "a non-profit making, permanent institution, in the service of society and of its development, and open to the public, which acquires, conserves, researches and communicates, and exhibits for the purpose of study, education and enjoyment, material evidence of people and their environment." As no-profit organisations, museums are strongly embedded in the institutional environment where they are located, especially because the institutions are the major source of financing (Ginsburgh and Mairesse, 1997).

"We have a strong connection with the local municipality, they sustain us with a financial support, also for the maintenance of the IT structure, which is very expensive."

In addition to be the most important source of financing, the institutional environment is also a potential source of marketing activities, opportunities of development and a potential incubator for building a strong network. In this perspective, the museum manager has the major role of handling and promoting the connections with institutional actors and opening up new partnership opportunities (Rosenstein, 2010).

Also, the informal relation of the managers with external actors has a key role (Reagans and McEvily, 2003). As the manager has reported:

"I know almost every single people involved with politics and local authorities, they help us especially with European projects and fund raise. But the important aspect here is that they do not help me because I am the museum manager, they help me because our informal ties."

\subsubsection{The importance of technology for museum management}

The digitalisation of museums has constituted a significant change of the tasks and duties of museum professionals. In fact, the introduction of digital tools requires a constant interaction with a wide variety of different information resources, including the museum's collections, information about collections, and information about the contexts in which collections are displayed, studied, and interpreted (Marty, 2007). To succeed at their jobs, museum professionals need to be comfortable also with handling the digital tools and the eventual information representations of museum artefacts (Cameron, 2003), developing organisation schemas for storing and providing access to museum records (Coburn and Baca, 2005), and using collections management systems (Hamma, 2005). 
"I did not expect to become suddenly a computer tech. I was used to receive question about artifacts and antiquities, and now I am continuously asked to setup the computers, fixing errors, explaining how the virtual experience works, rather that explaining history and archeology."

"Our role has been revolutionized, everything has changed. People are almost not interested anymore in expositions, are more interested in playing with those modernity."

Over the past few decades, many new technologies have been introduced into museums, with the result that museum professionals frequently rely on information technologies to complete even the basic tasks required keep the museum functioning (Jörgensen, 2004).

In this perspective, museums professionals have seen their role and tasks changing, from the pure cultural heritage curatorship to assist visitors with augmented reality, digital tools, digital collections (Gerrard, 1997). Museum professionals are shifting their jobs and developing new skills with digitisation and digital imaging, that have become increasingly important as museums offer visitors access to digital versions of their collections (Schaper et al., 2018).

\section{Discussion and conclusions}

By interviewing the team member of an Italian museum which has experienced a digitalisation process, we unveiled the unobserved dynamics beyond such impacting change and in particular, the relevance of the managerial leadership in the shape of the top manager.

The importance played by museum's actor is beyond dispute. In the last years, museum have experienced an overall period of crisis, due to the global financial crisis that has produced dramatic effects on cultural activities and museum. In fact, in many European countries, economic crisis has generated a drastic decrease in public and private financial support for culture and museums. The primary role of governments and institutions in addressing resources for museums and in promoting museums' growth makes them the fundamental actor to foster museum professional competencies, encouraging synergies between other cultural institutions such as schools and universities or between public and private organisations and partnerships in order to guarantee the sustainable management of museums and cultural heritage. Beyond the importance of the institutions, also the managerial team plays a central role (Barney and Wright, 1998; Guest, 1987): a qualified museum personnel is a key component to ensure the development of museum activities and to ensure a substantial exploitation of museum heritage. Under this perspective, the change of the managerial team has constituted a turning point for the Archaeological Museum of Atina, reflecting the importance of the management's role in shaping the organisational culture. In fact, the new management staff has activated the multimedia space, has designed the interactive experiences together with other cultural heritages of the areas, and has been engaged in promoting the museum among schools and other potential visitors. For those reason, the managerial team is a fundamental component of the realisation of an effective museum experience. 


\section{Limitations}

We acknowledge the fact that the study carries some unquestionable limitations, inherent also the specificity and the novelty of the observed phenomenon. First of all, the limitations accounted into the methodology, i.e., subjectivity of the researcher, uniqueness of results and consequent not replicability, and issues related to the validity and generalisability of the research constructs. Second, the breadth of the case analysed, which may hamper the overall relevance of the contribution; third, the 'disturbance effect' of other exogeneous, not-controlled variables, which may have played a crucial role during the transition but have not emerged from the data and they have not been deemed into the analysis.

This study contributes to the literature of the museum digitalisation as well as the literature of museum management by providing a theoretical missing link between the process of digitalisation and the importance of the managerial team. This study provides also contributions for practitioners, emphasising their relevant role in a deep transformational challenge such as digitalisation process and how to orchestrate a successful museum digitalisation. We also advise policy makers, which in no-profit cultural institutions like museum play a critical role to consider the role of the manager and the management team in addressing such a revolutionary changing.

Despite its undoubted limitations, the paper unveils an interesting aspects of museum digitalisation that need to be further unveiled with additional case studies, to support or enrich our findings.

\section{References}

Agocs, C. (1997) 'Institutionalized resistance to organizational change: denial, inaction and repression', Journal of Business Ethics [online] https://doi.org/10.1023/A:1017939404578.

Ansari, S.S., Reinecke, J. and Spaan, A. (2014) 'How are practices made to vary? Managing practice adaptation in a multinational corporation', Organization Studies [online] https://doi.org/10.1177/0170840614539310.

Barney, J. and Felin, T. (2013) 'What are microfoundations?', Academy of Management Perspectives [online] https://doi.org/10.5465/amp.2012.0107.

Barney, J.B. and Wright, P.M. (1998) 'On becoming a strategic partner: the role of human resources in gaining competitive advantage', Human Resource Management, Vol. 37, No. 1, pp.31-46 [online] https://onlinelibrary.wiley.com/doi/pdf/10.1002/(SICI)1099-050X(199821) 37:1\%3C31::AID-HRM4\%3E3.0.CO;2-W.

Bassanini, A., Scarpetta, S. and Hemmings, P. (2001) 'Economic growth: the role of policies and institutions. Panel data evidence from OECD countries', SSRN Electronic Journal [online] https://doi.org/10.2139/ssrn.265091.

Becker, M.H. (1970) 'Sociometric location and innovativeness: reformulation and extension of the diffusion model', American Sociological Review, Vol. 35, No. 2, p.267 [online] https://doi.org/10.2307/2093205.

Brettel, M., Keller, M. and Rosenberg, M. (2014) 'How virtualization, decentralization and network building change the manufacturing landscape: an Industry 4.0 perspective', World Academy of Science, Engineering and Technology International Journal of Information and Communication Engineering, Vol. 8, No. 1 [online] http://waset.org/publications/9997144. 
Burgess, N., Strauss, K., Currie, G. and Wood, G. (2015) 'Organizational ambidexterity and the hybrid middle manager: the case of patient safety in UK hospitals', Human Resource Management [online] https://doi.org/10.1002/hrm.21725.

Camarero, C., Garrido, M.J. and Vicente, E. (2011) 'How cultural organizations' size and funding influence innovation and performance: the case of museums', Journal of Cultural Economics, Vol. 35, No. 4, p.247 [online] https://doi.org/10.1007/s10824-011-9144-4.

Cameron, F. (2003) 'Digital futures I: museum collections, digital technologies, and the cultural construction of knowledge', Curator: The Museum Journal, Vol. 46, No. 3, pp.325-340 [online] https://doi.org/10.1111/j.2151-6952.2003.tb00098.x.

Carrozzino, M. and Bergamasco, M. (2010) 'Beyond virtual museums: experiencing immersive virtual reality in real museums', Journal of Cultural Heritage, Vol. 11, No. 4, pp.452-458 [online] https://doi.org/10.1016/j.culher.2010.04.001.

Chia, R. (2002) 'Essai: time, duration and simultaneity: rethinking process and change in organizational analysis', Organization Studies [online] https://oi.org/10.1177/ 0170840602236007.

Coburn, E. and Baca, M. (2005) 'Beyond the gallery walls: tools and methods for leading end-users to collections information', Bulletin of the American Society for Information Science and Technology, Vol. 30, No. 5, pp.14-19 [online] https://doi.org/10.1002/bult.323.

Cummings, T. (2008) 'Organization development and change', in Dynamics of Organizational Change and Learning [online] https://doi.org/10.1002/9780470753408.ch2.

Cummings, T.G. and Worley, C.G. (2009) Organization Development \& Change. 9th ed., South Western., Cengage Learning, Mason.

Daly, E. and Ballantyne, N. (2009) 'Retelling the past using new technologies: a case study into the digitization of social work heritage material and the creation of a virtual exhibition', Journal of Technology in Human Services [online] https://doi.org/10.1080/15228830802458590.

DuBrin, A.J. (2013) 'Organization development and change', in Fundamentals of Organizational Behavior [online] https://doi.org/10.1016/b978-0-08-022252-3.50023-0.

Eisenhardt, K.M. (1989) 'Building theories from case study', Academy of Management Review [online] https://doi.org/10.5465/AMR.1989.4308385.

Felin, T. and Foss, N.J. (2012) 'The (proper) microfoundations of routines and capabilities: a response to Winter, Pentland, Hodgson and Knudsen', Journal of Institutional Economics [online] https://doi.org/10.1017/S1744137411000506.

Ford, J.D., Ford, L.W., Amelio, A.D. and Ford, D. (2014) 'Resistence to change: the rest of the story perspective', Academy of Management Review [online] https://doi.org/10.5465/AMR. 2008.31193235.

Garrido, M.J. and Camarero, C. (2010) 'Assessing the impact of organizational learning and innovation on performance in cultural organizations', International Journal of Nonprofit and Voluntary Sector Marketing, pp.215-232 [online] https://doi.org/10.1002/nvsm.384.

Gavetti, G. (2005) 'Cognition and hierarchy: rethinking the microfoundations of capabilities' development', Organization Science [online] https://doi.org/10.1287/orsc.1050.0140.

Gerrard, R. (1997) 'The wired museum: emerging technology and changing paradigms. A review', Archives and Museum Informatics, Vol. 11, No. 2, pp.191-195 [online] https://doi.org/ 10.1023/A:1009034031986.

Gilbert, C.G. (2005) 'Unbundling the structure of inertia: resource versus routine rigidity', Academy of Management Journal [online] https://doi.org/10.5465/AMJ.2005.18803920.

Ginsburgh, V. and Mairesse, F. (1997) 'Defining a museum: suggestions for an alternative approach', Museum Management and Curatorship [online] https://oi.org/10.1080/ 09647779700301601.

Griffin, D.J.G. (1987) 'Managing in the museum organization. I. Leadership and communication', Museum Management and Curatorship [online] https://doi.org/10.1016/0260-4779(87)900215. 
Guest, D.E. (1987) 'Human resource management and industrial relations', Journal of Management Studies, September, Vol. 2 [online] https://onlinelibrary.wiley.com/doi/pdf/10.1111/j.14676486.1987.tb00460.x.

Hambrick, D.C. and Mason, P.A. (1984) 'Upper echelons: the organization as a reflection of its top managers', Academy of Management Review, Vol. 9, No. 2, pp.193-206 [online] https://doi.org/10.5465/amr.1984.4277628.

Hamma, K. (2005) 'Becoming digital', Bulletin of the American Society for Information Science and Technology, Vol. 30, No. 5, pp.11-13 [online] https://doi.org/10.1002/bult.322.

Hannan, M.T. and Freeman, J. (2006) 'Structural inertia and organizational change', American Sociological Review [online] https://doi.org/10.2307/2095567.

Helfat, C.E. and Peteraf, M.A. (2015) 'Managerial cognitive capabilities and the microfoundations of dynamic capabilities', Strategic Management Journal [online] https://doi.org/10.1002/ smj.2247.

Hooper-Greenhill, E. (1999) 'Education, communication and interpretation: towards a critical pedagogy in museums', The Educational Role of The Museum, https://doi.org/10.1080/03634528709378635.

Jörgensen, C. (2004) 'Unlocking the museum: a manifesto', Journal of the American Society for Information Science and Technology, Vol. 55, No. 5, pp.462-464 [online] https://doi.org/ 10.1002/asi.10396.

Kelly, D. and Amburgey, T.L. (2018) 'Organizational inertia and momentum: a dynamic model of strategic change', Academy of Management Journal [online] https://doi.org/10.5465/256407.

Kimberly, J.R. and Evanisko, M.J. (1981) 'Organizational innovation: the influence of individual, organizational, and contextual factors on hospital adoption of technological and administrative innovations', Academy of Management Journal, Vol. 24, No. 4, pp.689-713 [online] http://www.ncbi.nlm.nih.gov/pubmed/10253688.

Marty, P.F. (2007) 'Museum professionals and the relevance of LIS expertise', Library and Information Science Research [online] https://doi.org/10.1016/j.lisr.2006.10.008.

Mcloughlin, C. and Lee, M.J.W. (2010) 'Personalised and self regulated learning in the Web 2.0 era: international exemplars of innovative pedagogy using social software', Australasian Journal of Educational Technology, Vol. 26, No. 1, pp.28-43 [online] http://etec.ctlt.ubc.ca/ 510wiki/images/5/54/49023651.pdf.

Noh, S. and Tolbert, P.S. (2019) 'Organizational identities of U.S. art museums and audience reactions', Poetics, Vol. 72, pp.94-107 [online] https://doi.org/10.1016/J.POETIC.2018.10. 002.

Pallud, J. (2017) 'Impact of interactive technologies on stimulating learning experiences in a museum', Information \& Management, Vol. 54, No. 4, pp.465-478 [online] https://doi.org/ 10.1016/J.IM.2016.10.004.

Pallud, J. and Straub, D.W. (2007) 'Real vs. virtual: a theoretical framework for assessing the role of authenticity in visitor interactions with museum technologies', Association for Information Systems - 13th Americas Conference on Information Systems, AMCIS 2007: Reaching New Heights.

Proctor, N. (2010) 'Digital: museum as platform, curator as champion, in the age of social media', Curator: The Museum Journal [online] https://doi.org/10.1111/j.2151-6952.2009.00006.x.

Reagans, R. and McEvily, B. (2003) 'Network structure and knowledge transfer: the effects of cohesion and range', Administrative Science Quarterly [online] https://doi.org/10.2307/ 3556658 .

Rodrik, D., Subramanian, A. and Trebbi, F. (2004) 'Institutions rule: the primacy of institutions over geography and integration in economic development*', Journal of Economic Growth, Vol. 9 [online] https://link.springer.com/content/pdf/10.1023/B:JOEG.0000031425.72248.85. pdf. 
Rosenstein, C. (2010) 'When is a museum a public museum? Considerations from the point of view of public finance', International Journal of Cultural Policy, Vol. 16, No. 4, pp.449-465 [online] https://doi.org/10.1080/10286630902935178.

Schaper, M.M., Santos, M., Malinverni, L., Zerbini Berro, J. and Pares, N. (2018) 'Learning about the past through situatedness, embodied exploration and digital augmentation of cultural heritage sites', International Journal of Human-Computer Studies, Vol. 114, pp.36-50 [online] https://doi.org/10.1016/J.IJHCS.2018.01.003.

Schein, E.H. (2006) 'Culture: the missing concept in organization studies', Administrative Science Quarterly [online] https://doi.org/10.2307/2393715.

Solima, L., Peruta, M.R.D. and Maggioni, V. (2016) 'Managing adaptive orientation systems for museum visitors from an IoT perspective' [online] https://doi.org/10.1108/BPMJ-08-20150115.

Soren, B.J. (2009) 'Museum experiences that change visitors', Museum Management and Curatorship, Vol. 24, No. 3, pp.233-251 [online] https://oi.org/10.1080/ 09647770903073060.

Strauss, A. and Corbin, J. (1998) In Basics of Qualitative Research: Grounded Theory Procedures and Techniques, Newbury [online] https://doi.org/10.4135/9781452230153.

Teece, D.J. (2007) 'Explicating dynamic capabilities: the nature and microfoundations of (sustainable) enterprise performance', Strategic Management Journal [online] https://doi.org/10.1002/smj.640.

Tripsas, M. and Gavetti, G. (2002) 'Capabilities, cognition, and inertia: evidence from digital imaging', Strategic Management Journal [online] https://doi.org/10.1002/1097-0266(200010/ 11)21:10/11<1147::aid-smj128>3.3.co;2-i.

Tsoukas, H. and Chia, R. (2002) 'On organizational becoming: rethinking organizational change', Organization Science [online] https://doi.org/10.1287/orsc.13.5.567.7810.

Van De Ven, A.H. and Poole, M.S. (2005) 'Alternative approaches for studying organizational change', Organization Studies [online] https://doi.org/10.1177/0170840605056907.

Van de Ven, A.H. and Sun, K. (2018) 'Breakdowns in implementing models of organization change', Academy of Management Perspectives [online] https://doi.org/10.5465/amp.25.3. zol58.

Volkoff, O., Strong, D.M. and Elmes, M.B. (2007) 'Technological embeddedness and organizational change', Organization Science [online] https://doi.org/10.1287/orsc.1070.0288.

Weinberg, M.L. and Lewis, M.S. (2009) 'The public value approach to strategic management', Museum Management and Curatorship [online] https://doi.org/10.1080/09647770903073086.

Yin, R.K. (1981) ‘The case study as a serious research strategy', Science Communication [online] https://doi.org/10.1177/107554708100300106.

Yin, R.K. (2009) 'Identifying your case (s) and establishing the logic of your case study', in Case Study Research: Design and Methods [online] https://doi.org/10.1097/FCH. 0b013e31822dda9e.

Yin, R.K. (2014) Case Study Research: Design and Methods, 5th ed., SAGE Publications, Thousand Oaks, CA.

Yoshimura, Y., Sobolevsky, S., Ratti, C., Girardin, F., Carrascal, J.P., Blat, J. and Sinatra, R. (2014) 'An analysis of visitors' behavior in The Louvre Museum: a study using Bluetooth data', Environment and Planning B: Planning and Design, Vol. 41, pp.1113-1131 [online] https://doi.org/10.1068/b130047p. 